\title{
Relative Performance of Promising Chickpea (Cicer arientinum L.) Lines under Drought Stress Milieu
}

\author{
Muhammad Akhtar', Muhammad Tariq Mahmood ${ }^{2 *}$, Kaiser Latif Cheema1, Mushtaq Ahmad ${ }^{2}$, \\ Muhammad Jahanzaib Khalid ${ }^{1}$, Amir Amin ${ }^{1}$, Javed Anwar Shah ${ }^{1}, Z_{\text {eeshan Qadeer }}{ }^{\text {and Zeshan Ali }}{ }^{3}$
}

${ }^{1}$ Pulses Research Institute, Ayub Agriculture Research Institute, Faisalabad Pakistan; ${ }^{2}$ Gram Breeding Research Station, Kallurkot, Pakistan; ${ }^{3}$ Plant Physiology Program, Crop Sciences Institute, National Agricultural Research Centre, Islamabad, Pakistan.

Abstract | Sustained drought, uneven rain falls, progressively depleting soil moisture and predominant
cultivation of chickpea under residual soil moisture condition are major causes of drastic decline in chickpea
productivity in Pakistan. Systematic breeding efforts are required for evaluation of available genetic material
to evolve drought tolerant chickpea cultivars for drought prone regions of the country. For this purpose, a
research experiment was conducted in moisture stress (drought) and non-stress conditions (irrigated) at
Gram Breeding Research Station, Kallurkot, Pakistan during 2019-20. Mean performance of various traits
revealed significant differences among all the included chickpea advance lines. Drought indices i.e. drought
tolerance efficiency (DTE), drought susceptibility (DSI) and yield reduction percentage were calculated to
identify the drought tolerant chickpea lines. Correlation analysis showed that the strains possessing higher
number of pods plant ${ }^{-1}$, more root length and maximum grain weight were comparatively least susceptible
to moisture stress along with higher yield potential. Results regarding drought indices also indicated that
relatively higher DTE, less DSI and minimum yield reduction percentage were revealed by KK-10001, KK-
10015, KK-10019 and Bhakkar-2011. Therefore, these advance lines possess best genetic constitution for
moisture stress tolerance and may be utilized further for chickpea genetic improvement program.
Received | June 18, 2021; Accepted | July 26,2021; Published | August 14,2021
*Correspondence $\mid$ Muhammad Tariq Mahmood, Gram Breeding Research Station, Kallurkot, Pakistan; Email: taqaisrani@gmail.com
Citation | Akhtar, M., M.T. Mahmood, K.L. Cheema, M. Ahmad, M.J. Khalid, A. Amin, J.A. Shah, Z. Qadeer and Z. Ali. 2021. Relative
performance of promising chickpea (Cicer arientinum L.) lines under drought stress milieu. Pakistan Journal of Agricultural Research, 34(4): 672-
677.
DOI $\mid$ https://dx.doi.org/10.17582/journal.pjar/2021/34.4.672.677
Keywords | Chickpea, DTE, DSI, Drought, Stress

\section{Introduction}

$\mathrm{C}$ hickpea (Cicer arientinum L.) is the most important pulse legume crop mainly grown on residual soil moisture under rain-fed conditions across the world (Shah et al., 2020). Under arid environments, chickpea crop faces terminal drought resulting in drastic decline in productivity (Sharma et al., 2020). The cultivated area in Pakistan under chickpea crop is about 2.2 million hectares out, of which more than $80 \%$ of the national cropped area is shared solely by Thal Doab, Punjab, Pakistan (Rafiq et al., 2020). Chickpea occupies a very important place in farming system of Thal region and is the only crop which can grow in less fertile sand dunes and interdunal valleys (Khan et al., 2017). In Pakistan, chickpea is leading pulse legume crop in terms of area under crop but in production it is far below than the average world production (Shaheen et al., 2017; Nadeem et al., 2019). This production gap is attributed to various 
biotic and abiotic stresses. Drought is considered as major constraint limiting the chickpea productivity per unit area (Devasirvatham and Tan, 2018).

Breeding approaches for development of drought resilient chickpea cultivars have been emphasized by several researchers. In this instance, (Sabaghpour et al., 2006) assessed drought tolerance in chickpea genotypes and concluded that drought tolerance scores of morpho-yield traits may be used as selection criteria. Salimath et al. (2007) studied the drought tolerant germplasm introduced from different countries of the world. They explored genetic variation, drought tolerance and higher yield potential to identify the superior chickpea genotypes in collaboration with International Centre for Agriculture Research in Dry Areas (ICARDA). They concluded that diverse or contrasting parents are mated to create genetic variability for desired characteristics into the off springs and such variations can be exploited for genetic improvement to create moisture stress tolerance. Imtiaz and Malhotra, 2009 identified 50 chickpea genotypes at ICARDA and the genotypes selected were sent to different regions of world for inclusion in chickpea drought tolerance improvement program.

Droughtstressseverelyaffects thechickpeaproductivity and is generally unpredictable in occurrence, severity and duration due to uneven rainfalls during the crop period (Pandey et al., 2017). Likewise, Maqbool et al. (2017), studied drought tolerance mechanism in chickpea genotypes and narrated that moisture stress exerts severe effects on yield and yield components. Systematic breeding efforts are required to explore the available germplasm and to develop drought tolerant chickpea cultivars. Drought is major limiting factor for chickpea productivity and cultivation of chickpea crop under drought stress environment causes up to 50\% yield losses (Shah et al., 2020).

Sustained drought, dry spells, less and uneven rainfalls are major factors for low chickpea productivity in drought-prone regions of country (Jan et al., 2020). Chickpea crop in Thal area suffers extreme moisture stress and drought is considered as most adverse environment responsible for drastic decline in chickpea productivity (Rafiq et al., 2020). Therefore, it is direly needed to explore the genetic material for moisture stress tolerance and drought efficient genotypes. For screening of drought tolerant germplasm, field evaluation have been found most efficient tool and extensively utilized by several researchers (Gupta et al., 1995; Deshmukh et al., 2004; Sabaghpour et al., 2006; Bakhsh et al., 2007; Talebi et al., 2013; Hussain et al., 2015; Rafiq et al., 2020). The present study was planned to explore drought tolerance and to identify the most efficient strains for inclusion in chickpea drought tolerance improvement program.

\section{Materials and Methods}

The present research involving seventeen promising chickpea advance lines along with two commercial cultivars was conducted at Gram Breeding Research Station, Kallurkot, Pakistan (latitude $32.923^{\circ}$ and longitude $71.153^{\circ}$ ). Included advance lines were laid down in tri-replicate RCBD design under moisture stress environment $\left(\mathrm{I}_{0}\right)$ and irrigated conditions (I). A single irrigation was done to drought stress set to produce the essential soil moisture for germination while two extra irrigations were applied to irrigated set. $78 \mathrm{~mm}$ rainfall was received in 3 spells during the crop period. Sowing of entries was done by dibbler in 4 rows, $30 \mathrm{~cm}$ apart from each other measuring 4 meter length maintaining $10 \mathrm{~cm}$ plant-plant distance. Hoeing and all other recommended cultural practices were done during the crop period.

Data for root length $(\mathrm{cm})$, plant height $(\mathrm{cm})$, pods plant $^{-1}, 100$ grain weight $(\mathrm{g})$ was recorded from ten consecutive plants of each entry and averaged while days taken to physical maturity of plants were counted and yield $\left(\mathrm{kg} \mathrm{ha}{ }^{-1}\right)$ was recorded from each entry of both sets.

Data were subjected to analysis of variance as outlined by Steel et al. (1997). Correlation coefficient analysis was performed by the method outlined and practiced by Singh and Chaudhry (1979). While, drought indices were calculated by using the method of Fischer and Maurer (1978) and Fischer and Wood (1981).

$$
\mathrm{DSI}=(1-\mathrm{Yd} / \mathrm{Yp}) / \mathrm{D}
$$

$$
\begin{aligned}
& \text { Drought index }(D)=\frac{\text { Mean Yield of all genotypes in moisture stress }}{\text { Mean Yield of all genotypes in non stress }} \ldots \\
& \text { Yield Reduction } \%=\frac{\text { Yield in non stress }(\text { Yp) }- \text { Yield in stress }(\text { Yd) }}{\text { Yield in non stress }(Y p)} \times 100 \ldots \\
& \qquad \text { DTE (in percentage) }=\frac{\text { Yield in moisture stress }}{\text { Yield in non stress }} \times 100 \ldots \text { (d) }
\end{aligned}
$$

DTE: Drought tolerance efficiency; DSI: Drought susceptibility index; D: drought index; Yp: yield in 
non-stress, Yd: yield in stress.

\section{Results and Discussion}

Results regarding mean performance of chickpea strains revealed significant differences in performance of different included traits. Results (Table 1) revealed that undermoisturestress conditions rootlength ranged from 52-88 $\mathrm{cm}$ while under non-stress environment ranged from 41 to $66 \mathrm{~cm}$ indicating maximum root lengths under stress environment. Parameshwarappa et al. (2012) also reported similar findings regarding root length. Plant height was recorded between 20 $\mathrm{cm}$ to $63 \mathrm{~cm}$ under stress condition while in irrigated condition chickpea strains ranged between $42-80 \mathrm{~cm}$. Similarly, least number of pods (22-68) were counted under stress environment and higher range was recorded in irrigated environment (33-82). Under stress conditions maximum 100 grain weight (26.2 g) was recorded in KK-10001 while minimum was weighed in KK-10020 (22.2 g) while, in non-stress conditions maximum 100 grain weight was found in KK-10001 (26.4 gram) while minimum was recorded in KK-10005 (22.4 g). Under non-stress conditions, chickpea strains taken comparatively more days for physical maturity and ranged between152-172 days while, less days were recorded under stress environment (148-162 days). Our results agree to previous reports of (Ganjeali et al., 2005; Parameshwarappa et al., 2008).

Maximum yield under stress conditions was recorded in $\mathrm{KK}-10001$ (720 kg ha-1) followed by KK-100015 (680 kg ha-1), KK-10019 (650 kg ha1) and Bittle-2016 (570 kg ha-1) while under nonstress environment highest yield of $770 \mathrm{~kg} \mathrm{ha}^{-1}$ was recorded in KK-10001 followed by KK-10015 (740 $\left.\mathrm{kg} \mathrm{ha}{ }^{-1}\right)$, Bittle-2016 (735 kg ha-1) and KK-10019 $\left(720 \mathrm{~kg} \mathrm{ha}^{-1}\right)$. Yield performance of chickpea advance lines revealed that comparatively higher yields were recorded in irrigated environment and ranged from $410-770 \mathrm{~kg} \mathrm{ha}^{-1}$ the yield performances under stress environment (130-720 kg ha-1). (Deshmukh et al., 2004; Sabaghpour et al., 2006; Hussain et al., 2015) also found higher values for plant height, number of pods, 100 grain weight and final grain yield under non-stress environments.

Drought susceptibility index (DSI) of chickpea lines were calculated following the findings of Fischer and Maurer (1978) who reported that the genotypes
Table 1: Mean performance of different traits of chickpea genotypes under stress and non stress environment.

\begin{tabular}{|c|c|c|c|c|c|c|c|c|c|c|}
\hline & & & & & $\begin{array}{l}\text { Po } \\
\text { pla }\end{array}$ & & $100 C$ & $N$ & & \\
\hline & $\mathrm{D}$ & 1 & $\mathrm{D}$ & I & $\mathrm{D}$ & I & $\mathrm{D}$ & I & D & I \\
\hline & 88 & 6 & 54 & & 8 & 2 & 26.2 & 26.4 & 154 & 16 \\
\hline & 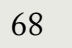 & & - & 64 & 32 & 54 & 2 & & & 16 \\
\hline & 56 & 50 & 5 & 69 & 26 & 4 & 4.5 & & 58 & 16 \\
\hline 5 & 9 & 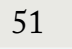 & 58 & 72 & 22 & 42 & 4 & . & 56 & 17 \\
\hline & r & . & 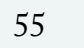 & 76 & 2 & 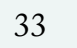 & 8 & & 1 & 15 \\
\hline & 52 & 44 & 32 & 58 & 15 & 34 & 4 & & 152 & 164 \\
\hline 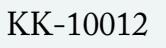 & 72 & 60 & 38 & 56 & 36 & 55 & 1 & 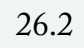 & 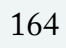 & 17 \\
\hline & 00 & & T & & 21 & 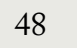 & & & 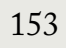 & 16 \\
\hline & 64 & 5 & 62 & 80 & 27 & 47 & 22.9 & & 15 & 168 \\
\hline 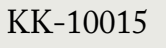 & 86 & 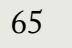 & 年 & 69 & - & 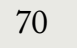 & 8 & 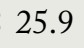 & . & 16 \\
\hline & 63 & & 36 & 54 & 19 & 38 & 2 & & 16 & 17 \\
\hline & 69 & 5 & 46 & 65 & 38 & 56 & 2 & 2 & 16 & 172 \\
\hline 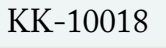 & 64 & $(0$ & 20 & 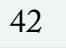 & 20 & ? & 2 & & 1 & 15 \\
\hline & 82 & 66 & Jo & 54 & 44 & 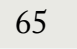 & .9 & 2 & 1 & 16 \\
\hline 0 & 60 & 41 & 48 & 63 & 26 & 45 & 2 & 8 & 1 & 170 \\
\hline & 56 & 20 & 50 & 60 & 24 & 44 & 23.4 & & 1 & 16 \\
\hline & 55 & 40 & 3 & 58 & 22 & 36 & 3.6 & 2 & 154 & 16 \\
\hline- & 78 & 52 & 54 & 64 & 50 & 63 & 4.2 & 2 & 155 & 16 \\
\hline ittle-2016 & 67 & נת & 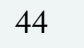 & 00 & 45 & 00 & 25.4 & & & 16 \\
\hline & 5.27 & & 725 & 8 & 05 & 8.82 & 16 & 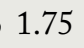 & 65 & 87 \\
\hline
\end{tabular}

D: Moisture stress conditions; I: Non-stress conditions; 100 GW:100 grain weight.

Table 2: Drought indices of chickpea genotypes.

$\begin{array}{llllll}\text { Entries } & \text { Yd } & \text { Yp } & \text { DSI } & \text { DTE \% } & \text { Y Rd \% } \\ \text { KK-10001 } & 720 & 770 & 0.11 & 93.5 & 6.5 \\ \text { KK-10002 } & 140 & 590 & 1.24 & 23.7 & 90.0 \\ \text { KK-10003 } & 270 & 500 & 0.69 & 54.0 & 46.0 \\ \text { KK-10005 } & 296 & 535 & 0.72 & 55.3 & 44.7 \\ \text { KK-10009 } & 190 & 510 & 1.05 & 37.3 & 62.7 \\ \text { KK-10011 } & 130 & 410 & 1.11 & 31.7 & 68.3 \\ \text { KK-10012 } & 280 & 616 & 0.88 & 45.5 & 54.5 \\ \text { KK-10013 } & 280 & 530 & 0.76 & 52.8 & 47.2 \\ \text { KK-10014 } & 270 & 514 & 0.77 & 52.5 & 47.5 \\ \text { KK-10015 } & 680 & 740 & 0.13 & 91.9 & 8.1 \\ \text { KK-10016 } & 242 & 468 & 0.78 & 51.7 & 48.3 \\ \text { KK-10017 } & 356 & 630 & 0.70 & 56.5 & 43.5 \\ \text { KK-10018 } & 290 & 525 & 0.73 & 55.2 & 44.8 \\ \text { KK-10019 } & 650 & 720 & 0.16 & 90.3 & 9.7 \\ \text { KK-10020 } & 270 & 515 & 0.77 & 52.4 & 47.6 \\ \text { KK-10021 } & 360 & 502 & 0.46 & 71.7 & 28.3 \\ \text { KK-10022 } & 250 & 480 & 0.78 & 52.1 & 47.9 \\ \text { Bhakkar-2011 } & 460 & 540 & 0.24 & 85.2 & 14.8 \\ \text { Bittle-2016 } & 570 & 735 & 0.36 & 77.6 & 22.4\end{array}$

Yd: Yield in stress conditions; Yp: Yield Non-stress conditions; MP: Mean productivity; DSI: Drought susceptibility index; DTE \%: Drought tolerance efficiency; $Y$ Rd: Yield reduction percentage. 
exhibiting reduced DSI values are less drought susceptible and more tolerant to moisture stress environment. Results revealed that least DSI (0.11) was recorded in KK-10001 followed by KK-10015 (0.13), KK-10019 (0.15) and Bhakkar-2011 (0.24) demonstrating that these strains are least susceptible to drought while highest DSI values were recorded in KK-10002 (1.24), KK-10011 (1.11) and KK-10009 (1.05) indicating that these genotypes are highly susceptible to drought (Table 2). Similarly, drought tolerance efficiency (DTE) of chickpea strains presented highest values for KK-10001 (93.5\%) followed by KK-10015 (91.9), KK-10019 (90.3\%) and Bhakkar-2011 (85.2\%). Likewise, least yield reduction percentage was also recorded in KK-10001 (6.5\%) followed by KK-10015 (8.1\%), KK-10019 (9.7\%) and Bhakkar-2011 (14.8\%) demonstrating that these genotypes were most drought tolerant. Graphical presentation of DTE, DSI and yield reduction percentage of chickpea was also done to illustrate their inter-relationship (Figure 1). It was noted that the lines with relatively high values of DTE presented least DSI and minimum yield reduction. Our results were in line with the former studies of (Yadav et al., 2005; Bakhsh et al., 2007; Jan et al., 2020).

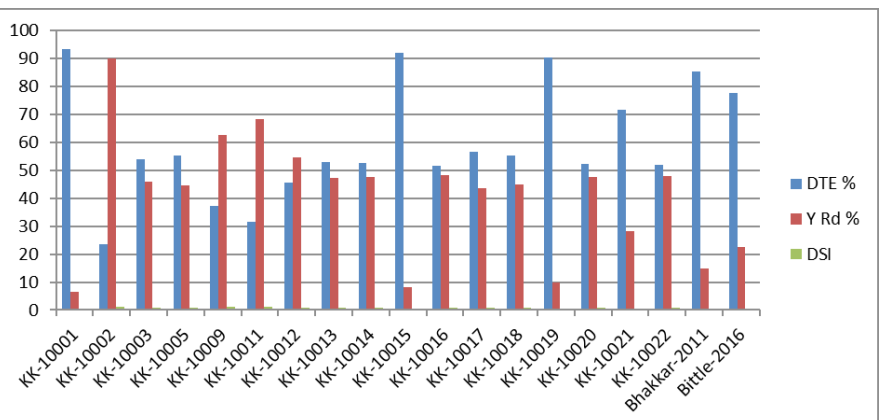

Figure 1: DTE, Yield reduction and DSI of chickpea genotypes.

Association of different traits of chickpea stains under moisture stress conditions was quantified through correlation coefficient analysis. Results (Table 3) revealed that DTE exhibited highest positive association to grain yield (0.94) followed by pod plant ${ }^{-1}(0.87)$, root length $(0.83)$ and $100 \mathrm{GW}$ (0.62) demonstrating that genotypes exhibiting higher values for DTE, pods plant-1, root length and $100 \mathrm{GW}$ posses higher yield potential while negative association was presented by DSI and days to maturity. Similarly, the DTE showed significantly positive correlation with pods plant $^{-1}(0.70)$, root length (0.64) and $100 \mathrm{GW}(0.45)$ while negatively correlated to DSI (0.99) and days to maturity (0.10). On the other hand, drought susceptibility index was negatively associated to pods plant ${ }^{-1}$, root length and $100 \mathrm{GW}$ indicating that the genotypes possessing more pods plant $^{-1}$ with longer roots and more grain weight are relatively less susceptible to drought stress. Similar performances of drought indices were already reported and are in line with the previous results of (Parameshwarappa et al., 2012; Hussain et al., 2015; Rafiq et al., 2020).

\section{Conclusions and Recommendations}

Drought tolerance efficiency, drought susceptibility and yield reduction percentage of chickpea advance lines were measured to evaluate the relative performance of promising chickpea strains under moisture stress conditions. Based on finding it was concluded that comparatively higher drought tolerance efficiency, minimum drought susceptibility and least yield reduction was found in KK-10001, KK-10015, KK-10019 and Bhakkar-2011. Therefore, these strains possess best genetic constitution for drought tolerance and may be incorporated in chickpea genetic advancement program for development of drought resilient chickpea cultivars.

Table 3: Correlation coefficients under stress environments.

$\begin{array}{lllllllll} & \text { RL } & \text { PH } & \text { PP } & \text { 100GW } & \text { DM } & \text { DSI } & \text { DTE } & \text { YLD } \\ \text { RL } & 1 & 0.453^{*} & 0.9450^{* *} & 0.7798^{* * *} & -0.0481 & -0.6400^{* *} & 0.6449^{* *} & 0.8350^{* * *} \\ \text { PH } & & 1 & 0.1368 & 0.1235 & 0.1465 & -0.2246 & 0.2147 & 0.1771 \\ \text { PP } & & & 1 & 0.7571^{* *} & -0.0572 & -0.7063^{* *} & 0.7096^{* *} & 0.8739^{* *} \\ 100 \mathrm{GW} & & & & 1 & 0.0415^{*} & -0.4628^{*} & 0.4590^{*} & 0.6274^{* *} \\ \text { DM } & & & & & 1 & 0.0928 & -0.1050 & -0.1159 \\ \text { DSI } & & & & & & 1 & -0.9992^{* *} & -0.9471^{* *} \\ \text { DTE \% } & & & & & & 1 & 0.9497^{* *} \\ \text { YLD } & & & & & & & & 1\end{array}$


Novelty Statement

Screening of advanced breeding lines rather than varieties for moisture stress tolerance to evolve drought tolerant chickpea cultivars for drought prone regions of the country is a novel research study and will be highly valuable for chickpea breeders and scientists.

\section{Author's Contribution}

MA: Conceived idea, gave technical inputs and supervised the research. MTM: Did overall management of the article, did analysis, wrote abstract, methodology and correspondence. KLC: Wrote results and discussion section and did necessary corrections, MA: Wrote introduction section of the article. MJK: Collected data for different traits. AA: Wrote conclusion, studied former studies and did citations. JAS: Checked plagiarism and made corrections. ZQ: Collected research data. ZA: Compiled research data and gave technical inputs at every step.

\section{Conflict of interest}

The authors have declared no conflict of interest.

\section{References}

Bakhsh, A., S.R. Malik, M. Aslam, U. Iqbal and A.M. Haqqani. 2007. Response of chickpea genotypes to irrigated and rain-fed conditions. Int. J. Agric. Biol., 4: 590-593.

Deshmukh, D.V., L.B. Mhase and B.M. Jamadagni. 2004. Evaluation of chickpea genotypes for drought tolerance. Indian J. Pulses Res., 17: 4749.

Devasirvatham, V. and D.Tan. 2018. Impact of high temperature and drought stresses on chickpea production. Agronomy, 8: 145. https://doi. org/10.3390/agronomy8080145

Fischer, K.S. and G. Wood. 1981. Breeding and selection for drought tolerance in tropical maize. In: Proc. Symp. on Principles and Methods in Crop Imprt. for Drought Resist. with Emphasis on Rice, IRRI, Philippines, 23-25 th May, 1981.

Fisher, R.A. and R. Maurer. 1978. Drought resistance in spring wheat cultivars. Grain yield responses in spring wheat. Aust. J. Agric. Sci., 29: 892-912. https://doi.org/10.1071/ AR9780897

Ganjeali A, M. Kafi, A. Bagheri and F. Shahriyari. 2005. Screening for drought tolerance on
Chickpea genotypes. Iran J. Field Crops Res., 3: 122-127.

Ghasemi, M. and E. Farshadfar. 2015. Screening drought tolerant genotypes in wheat using multivariate and stress tolerance score methods. Int. J. Biosci., 6: 326-333.

Gupta S.N., B.S. Dahiya, B.P.S. Malik and N.R. Bishnoi. 1995. Response of chickpea to water deficits and drought stress. Haryana Agric. Univ. Res. J., 251: 11-19.

Hussain, N., M. Aslam, A. Ghaffar, M. Irshad and Naeem-ud-Din. 2015. Chickpea genotypes evaluation for morpho-yield traits under water stress condition. J. Anim. Plant Sci., 25(1): 206211.

Imtiaz, M. and R.S. Malhotra. 2009. Reduce stress: Breed for drought tolerance. ICARDA Caravan; Sci. Food Secur., 26: 34-36.

Jan, M., T. Haq, H. Sattar, M. Butt, A. Khaliq, M. Arif and A. Rauf. 2020. Evaluation and screening of promising drought tolerant chickpea (Cicer arietinum L.) genotypes based on physiological and biochemical attributes under drought conditions. Pak. J. Agric. Res., 33(3): 662-672.https://doi.org/10.17582/ journal.pjar/2020/33.3.662.672

Khan, O.Z., A. Naseer, M. Shahbaz, S. Akhtar, M. Faisal and K. Mushtaq. 2017. Accessing the factors affecting the yield of Chick-pea in Thal, Punjab, Pakistan. J. Innov. Bio-Res., 1(1): 4651.

Maqbool, M.A., M. Aslam and H. Ali. 2017. Breeding for improved drought tolerance in chickpea (Cicer arietinum L.). Plant Breed., 136: 300-318. https://doi.org/10.1111/pbr.12477

Nadeem, M., J. Li, M. Yahya, A. Sher, C. Ma, X. Wang and L. Qiu. 2019. Research progress and perspective on drought stress in legumes. A review. Int. J. Mol. Sci., 20: 2541. https://doi. org/10.3390/ijms20102541

Pandey, P., V. Irulappan, M.V. Bagavathiannan and M. Senthil-Kumar. 2017. Impact of combined abiotic and biotic stresses on plant growth and avenues for crop improvement by exploiting physio-morphological traits. Front.Plant Sci., 8: 537. https://doi.org/10.3389/fpls.2017.00537

Parameshwarappa, S.G. and P.M. Salimath. 2008. Field screening of chickpea genotypes for drought resistance. Karnataka J. Agric. Sci., 21(1): 113-114.

Parameshwarappa, S.G., P.M. Salimath, H.D. 
Upadhyaya, S.S. Patil, S.T. Kajjidoni, B.C. Patil and Y.D. Narayana. 2012. Variation in root characters of selected drought tolerant accessions of chickpea (Cicer arietinum L.) grown under terminal drought. Karnataka J. Agric. Sci., 25(3): 389-391.

Rafiq, M., M.T. Mahmood, M. Ahmad, I. Ali, M. Saleem, I. Rasool and Z. Ali. 2020. Differential response of elite chickpea genotypes under moisture stress conditions. Pak. J. Agric. Res., 33(3): 422-428. https://doi.org/10.17582/ journal.pjar/2020/33.3.422.428

Reddy, A.R., K.V. Chaitanya and M. Vivekanandan. 2004. Drought-induced responses of photosynthesis and antioxidant metabolism in higher plants.J. Plant. Physiol., 161:1189-1202. https://doi.org/10.1016/j.jplph.2004.01.013

Rosielle, A.A. and J. Hamblin. 1981. Theoretical aspects of selection for yield in stress and non-stress environments. Crop Sci., 21: 943-946. https://doi.org/10.2135/ cropsci1981.0011183X002100060033x

Sabaghpour, S.H., A.K. Mahmodi, A. Saeed, M. Kamel and R.S. Malhotra. 2006. Study on chickpea drought tolerance lines under dryland condition of Iran. Indian J. Crop Sci., 1(1-2): 70-73.

Salimath, P.M., C. Toker, J.S. Sandhu, J. Kumar, B. Suma, S.S. Yadav and P.N. Bahl. 2007. Conventional breeding methods. In: Yadav, S.S., Redden, B., Chen, W., Sharma, B., editors. Chickpea breeding and management. $1^{\text {st }}$ ed. Wallingford (UK): CAB International. pp. 369-390. https://doi. org/10.1079/9781845932138.018

Shah, T.M., M. Imran, B.M. Atta, M.Y. Ashraf, A. Hameed, I. Waqar, M. Shafiq, K. Hussain, M.
Naveed, M. Aslam and M.A. Maqbool. 2020. Selection and screening of drought tolerant high yielding chickpea genotypes based on physiobiochemical indices and multi-environmental yield trials. BMC Plant Biol., 20(1): 171. https://doi.org/10.1186/s12870-020-02381-9

Shaheen, A. and M.A. Baig. 2011. Drought severity assessment in arid area of Thal doab using Remote Sensing and GIS. Int. J. Water Resour. Arid Environ., 1(2): 92-101.

Shaheen, I., Parveen, S. and Parveen, Z. 2017. Evaluation of Pongamia pinnata Products against the Sclerotium rolfsii Extracted from Chickpea. Adv Crop Sci Tech 5: 291. doi:10.4172/2329-8863.1000291

Sharma, N.K., S.K. Gupta, V. Dwivedi and D. Chattopadhyay. 2020. Lignin deposition in chickpea root xylem under drought. Plant Signal. Behav., 15(6): 1754621. https://doi.org/ 10.1080/15592324.2020.1754621

Singh, R.K. and B.D. Chaudhry. 1979. Biometrical methods in quantitative genetic analysis. Kalyani Publ., New Delhi, India.

Steel, R.G.D., J.H. Torrie and D.A. Dickey. 1997. Principles and procedures of statistics: A biometrical approach. $3^{\text {rd }}$ Edi. McGraw Hill Book Co., New York, USA

Talebi, R., M.H. Ensafi, N. Baghebani, E. Karami and K. Mohammadi. 2013. Physiological responses of chickpea (Cicer arietinum L.) genotypes todrought stress. Environ. Exp. Biol. 11: 9-15.

Yadav, S.R., R.M. Yadav and C. Bhushan. 2005. Genotypic differences in physiological parameters and yield of chickpea (Cicer arietinum L.) under soil moisture stress conditions. Legume Res., 28: 306-308. 